\title{
Differential MCMI-III Psychopathological Profiles Between Intimate Partner Violence Perpetrators with and without Childhood Family Violence
}

Short Title: Psychopathology and Childhood Violence in IPV

Sandra Siria $^{\mathrm{a}}$, Javier Fernández-Montalvo ${ }^{\mathrm{a}, \mathrm{b}}$, Jose A. Echauric ${ }^{\mathrm{c}}$, Alfonso Arteaga ${ }^{\mathrm{a}, \mathrm{b}}$, Juana M. Azkárate ${ }^{\mathrm{c}}$, and María Martínez ${ }^{\mathrm{c}}$

${ }^{a}$ Departament of Health Sciences. Universidad Pública de Navarra. Campus de Arrosadía. 31006 Pamplona. Spain.

${ }^{\mathrm{b}}$ Instituto de Investigación Sanitaria de Navarra (IdiSNA). Pamplona. Navarra. Spain. ${ }^{\mathrm{c}}$ Psimae. Instituto de Psicología Jurídica y Forense. Pamplona. Navarra. Spain.

\section{Corresponding Author:}

Javier Fernández-Montalvo. Department of Health Sciences. Universidad Pública de Navarra. Campus de Arrosadía. 31006 Pamplona. Spain.

Email: fernandez.montalvo@unavarra.es

Conflict of Interest: Authors declare no conflict of interest.

Acknowledgements: The authors would like to thank the Social Service of Justice of the Government of Navarre, Spain, for their assistance in developing this research. Data Availability: Data belong to the Navarre Government (Spain) and consequently data cannot be made openly available.

Funding: This research did not receive any specific grant from funding agencies in the public, commercial, or not-for-profit sectors. 


\begin{abstract}
This study explored the differential prevalence of personality disorders (PD) and clinical syndromes between male perpetrators of intimate partner violence (IPV) with and without a history of childhood family violence (CFV). A sample of 981 perpetrators of IPV was assessed with the Millon Clinical Multiaxial Inventory-III (MCMI-III). Comparisons of sociodemographic characteristics and MCMI-III scales' scores between perpetrators with $(n=293)$ and without $(n=688)$ CFV were carried out. Results showed that IPV perpetrators with CFV had a lower level of education, were less frequently employed, and had higher rates of previous psychiatric history than perpetrators without CFV. Statistically significant differences between groups in almost all the MCMI-III scales were found. Perpetrators with CFV presented with higher scores on most of the evaluated scales and showed a more severe psychopathological profile than perpetrators without $\mathrm{CFV}$. The multivariate analysis showed that the main MCMI-III domains related to CFV were higher scores on the disclosure and alcohol dependence scales and lower scores on the passive-aggressive scale. These findings reveal that $\mathrm{CFV}$ is associated with a more severe psychopathological profile in perpetrators of IPV. In order to develop tailored interventions, the presence of CFV and psychopathological symptoms should be assessed in IPV perpetrators.
\end{abstract}

Keywords: intimate partner violence, psychopathology, male perpetrators, childhood family violence, MCMI-III

This is the peer reviewed version of the following article: Siria, S, FernándezMontalvo, J, Echauri, JA, Arteaga, A, Azkárate, JM, Martínez, M. Differential MCMI-III psychopathological profiles between intimate partner violence perpetrators with and without childhood family violence. Clin Psychol Psychother. 2021; 1- 10, which has been published in final form at https://doi.org/10.1002/cpp.2557. This article may be used for noncommercial purposes in accordance with Wiley Terms and Conditions for Use of Self-Archived Versions.

Siria, S., Fernández-Montalvo J., Echauri J. A., Arteaga, A., Azkárate, J.M., Martínez, M. (2021). Differential MCMI-III psychopathological profiles between intimate partner violence perpetrators with and without childhood family violence. Clinical Psychology \& Psychotherapy. https://doi.org/10.1002/cpp.2557 


\section{Key Practitioner Message:}

- IPV perpetrators with CFV have a more severe psychopathological profile than those without CFV.

- Compulsive personality disorder is the most prevalent among the overall sample.

- Alcohol dependence reached the highest score among clinical syndromes for the whole sample.

- Individually-tailored strategies may increase success in intervention programs for IPV perpetrators and CFV should be assessed. 
Differential MCMI-III Psychopathological Profiles between Intimate Partner Violence Perpetrators with and without Childhood Family Violence

A number of studies have tried to identify intimate partner violence (IPV) perpetrators' personality characteristics and the presence of psychopathological symptoms as an attempt to better understand this type of violence, identify treatment targets, and prevent recidivism (Elklit et al., 2018; Green \& Browne, 2020; Walker et al., 2015). It is important to evaluate personality traits among male perpetrators of IPV because different personality disorders (PD) often require distinct treatment interventions (Weber \& Bouman, 2020). Even though not all the IPV perpetrators present with a psychopathological diagnosis (Craig, 2003; Weber \& Bouman, 2020) and there is no causal link between psychopathology and the perpetration of violence, there are some PD that are commonly present in this population (Craig, 2003; Novo et al., 2012). Additionally, a history of childhood family violence (CFV) plays a significant role in the perpetration of IPV (Afifi et al., 2017; Davis et al., 2018; Hilton et al., 2019) and in the development of further psychopathology (Afifi et al., 2011; Anda et al., 2006; Fernández-Montalvo et al., 2020; Marackova et al., 2016). Some studies have identified that personality disorder traits mediate the consequences of CFV on the perpetration of IPV (Ehrensaft et al., 2006; Liu et al., 2012; Murphy et al., 1993). Therefore, the relationship between CFV, IPV and psychopathology should be more deeply studied to extend the limited literature available in this field.

The Millon Clinical Multiaxial Inventory (MCMI) is one of the most widely used personality measures in the assessment of clinical disorders (Craig, 2003). It allows clinicians to distinguish between PD, which reflect long-standing chronic characteristics, and clinical syndromes, which can be defined as symptomatic features of an individual's current condition (Walker et al., 2015). Due to its utility, it has been 
extensively used to evaluate the personality characteristics of male IPV perpetrators. Nevertheless, caution should be paid when interpreting the results regarding levels of psychopathology, because MCMI tends to over-diagnose PD in comparison with clinical interviews (Fernández-Montalvo \& Echeburúa, 2008). Moreover, Murphy et al. (1993) found evidence that the scores of the evaluated disorders were attributable to response styles and negative affectivity. Hence, the three validity scales of the MCMI (disclosure, desirability, and debasement) should be considered when these types of assessment tools are used within IPV perpetrators populations, given the social desirability and the denial that is frequently present among them (Catalá-Miñana et al., 2014; Craig, 2003; Johnson et al., 2006).

In general, although several samples of IPV perpetrators produce normal MCMI profiles (Craig, 2003), research has shown that male perpetrators are twice as likely as non-perpetrators to have any psychiatric disorder (Okuda et al., 2015; Shorey et al., 2012). More specifically, when the MCMI has been used to assess PD and clinical personality traits among male perpetrators of IPV, the prevalence rates have varied between 28\% and 88\% (Boira \& Jodrá, 2010; Corral \& Calvete, 2014; Craig, 2003; Elklit et al., 2018; Fernández-Montalvo \& Echeburúa, 2008; Gibbons et al., 2011). Variations in the percentages might be due to the use of different versions of the MCMI, the diversity of sample sources, and cultural differences (Catalá-Miñana et al., 2014; Gondolf, 1999). There is no unique IPV perpetrator personality profile (Craig, 2003; Elklit et al., 2018; Gibbons et al., 2011; Walker et al., 2015); however, some PD and clinical syndromes have been found to be the most prevalent among them. Research evaluating this population through the MCMI questionnaire has found that the most frequent PD were antisocial, narcissistic, obsessive-compulsive, and borderline, while drug and/or alcohol dependence were the most predominant clinical syndromes

Siria, S., Fernández-Montalvo J., Echauri J. A., Arteaga, A., Azkárate, J.M., Martínez, M. (2021). Differential MCMI-III psychopathological profiles between intimate partner violence perpetrators with and without childhood family violence. Clinical Psychology \& Psychotherapy. https://doi.org/10.1002/cpp.2557 
(Arteaga et al., 2015; Catalá-Miñana et al., 2014; Corral \& Calvete, 2014; Craig, 2003;

Elklit et al., 2018; Fernández-Montalvo \& Echeburúa, 2008; Gibbons et al., 2011;

Gondolf, 1999; Johnson et al., 2006; Murphy et al., 1993; Walker et al., 2015).

A history of family victimization during childhood, along with other risk factors, has been shown to be related to a higher likelihood of perpetrating IPV later in life (Afifi et al., 2017; Okuda et al., 2015; Roberts et al., 2011). Additionally, CFV is also a robust risk factor for the development of PD in adulthood (Afifi et al., 2011; Anda et al., 2006; Grover et al., 2007; Kessler et al., 2010). One study conducted to classify IPV offender subtypes according to personality disorders using the MCMI found an association between offender type and the presence of CFV (Johnson et al., 2006). These authors demonstrated that the so-called "low pathology" group of male perpetrators of IPV reported the lowest frequency of CFV and presented with the most moderate levels of general psychopathology. However, only $12 \%$ of their sample fit into this category. At the same time, the so-called "borderline" group, into which $28 \%$ of the sample fell, presented the highest frequency of CFV. This group scored high not only on the borderline scale but also on a number of additional scales, such as alcohol dependence and major depression. Other studies have also shown that borderline and antisocial PD are significantly related to CFV among male perpetrators (Green \& Browne, 2020; Liu et al., 2012). In summary, psychopathological factors have been revealed as mediators between CFV and IPV perpetration (Ehrensaft et al., 2006; Liu et al., 2012; Roberts et al., 2011).

Exposure to CFV and to other negative or adverse experiences during childhood is associated with adult personality and psychological traits (Afifi et al., 2011; Grusnick et al., 2020; Marackova et al., 2016). As Roberts et al. (2011) suggest, research should 
highlight the sets of factors (e.g., individual, family, socioeconomic, contextual, and cultural factors) across all the life stages — childhood, adolescence, and adulthood— from a dynamic life-course perspective. The presence of difficulties in emotional regulation might be associated with CFV, PD, and IPV (Roberts et al., 2011; Shorey et al., 2012). It is not easy to explain the etiology of IPV, because the processes underlying these elements are long-term complex links related to additional risk and protective factors (Liu et al., 2012). Nevertheless, although this pathway might elucidate only a part of IPV perpetration, it seems crucial to consider and analyze in depth this triadic interrelation.

Previous research has shown the relevance of the presence of CFV among male perpetrators of IPV. The exposure to family violence during childhood has been associated with a more severe psychopathological profile and a higher rate of psychiatric history (Afifi et al., 2017; Davis et al., 2018; Fernández-Montalvo et al., 2020; Lee et al., 2013; Liu et al., 2012). This study is an attempt to further examine the importance of the psychopathological consequences of CFV and its link to the development of IPV perpetration. The research goals are the following: (1) to estimate the prevalence of the MCMI-III personality disorders and clinical syndromes in a sample of Spanish male IPV perpetrators; (2) to explore whether differential psychopathological personality traits exist between IPV perpetrators with and without CFV; and (3) to identify which of the MCMI-III variables are related to having a history of CFV among male IPV perpetrators. The main hypothesis was that those with a history of CFV would present with higher MCMI-III scores than those without CFV. This study forms part of a wider line of research into the relationship between CFV and the perpetration of IPV (Fernández-Montalvo et al., 2020). 


\section{Methods}

\section{Participants}

The initial sample in this study consisted of 1135 male perpetrators of IPV who were in a specialized treatment program due to having committed an offence related to gender violence against their female partners. This program is developed by PSIMAE (the Institute of Judicial and Forensic Psychology), which is directed by the Social Service of Justice of the Navarra Government, and provides treatment for all IPV perpetrators in Navarra (Spain). All the participants who began the treatment program from March 2009 to December 2019 were included in the study. None of them received a monetary compensation for participating in the study.

The sample inclusion criteria were as follows: (a) being older than 18 years of age; (b) having been involved in violence against a female partner; (c) not suffering from any serious mental disorder after being assessed by a clinical psychologist; (d) having knowledge of the Spanish language; and (e) signing the informed consent to participate in the study after having been properly informed of its characteristics.

Following application of the abovementioned inclusion criteria, 154 men (16.6\%) were excluded from the study. Of those, 20 refused to participate after being informed, and 134 did not meet the established criteria. Consequently, 981 subjects ( $86.4 \%$ of the initial sample) were studied.

The mean age of the total sample was 37.5 years $(S D=10.8$; range: $18-75)$, and nearly half of the sample (48.5\%) was Spanish. Moreover, 293 (29.9\%) had a history of CFV, and $688(70.1 \%)$ did not. Most of the participants were court-referred to the treatment program $(71.4 \%)$, others were imprisoned $(22.1 \%)$, and the remaining subjects $(6.5 \%)$ sought treatment voluntarily.

\section{Assessment Measures}

Siria, S., Fernández-Montalvo J., Echauri J. A., Arteaga, A., Azkárate, J.M., Martínez, M. (2021). Differential MCMI-III psychopathological profiles between intimate partner violence perpetrators with and without childhood family violence. Clinical Psychology \& Psychotherapy. https://doi.org/10.1002/cpp.2557 
The General Structured Interview of Batterer Men (Echeburúa \& FernándezMontalvo, 1998) consists of five sections that collect data on the respondents' demographic characteristics, potential labor problems, child and adolescent development, potential problems of IPV in previous relationships, the current situation with their partners, health status, criminal records, and social relations. It also explores psychopathological variables that are usually related to gender violence perpetrators (mainly jealousy and abuse of alcohol). This interview was also used to identify the self-reported presence and characteristics of CFV (physical, psychological, and/or sexual) among the participants in the sample, taking into account whether they had directly suffered or witnessed the abuse.

The Millon Clinical Multiaxial Inventory-III (MCMI-III) (Millon, 1997; Spanish version of Cardenal \& Sánchez, 2007) is a clinical questionnaire used to assess general psychiatric disorders, including PD, similar to those contained in the DSM-IV-TR. It is a self-report inventory consisting of 175 dichotomous items (true or false). It comprises 4 validity scales, 11 clinical personality pattern scales, 3 severe personality scales, 7 clinical syndrome scales, and 3 severe syndrome scales. The MCMI-III is interpreted using base-rate (BR) transformation scores. The presence of a BR score lower than 75 $(\mathrm{BR}<75)$ is considered not clinically relevant. When BR scores are between 74 and 85 , this suggests the presence of traits and symptoms associated with the disorder, albeit not at a diagnostic level. A BR score higher than $84(\mathrm{BR}>84)$ reflects a trait or symptom at the diagnostic level. The Spanish adaptation manifested alpha coefficients between .65 to .88 and a high test-retest reliability (.91) (Cardenal \& Sánchez, 2007).

\section{Procedure}

The protocol for this study was approved by the ethics committee of the XXX (identifying information removed) (code XXX). 
Once the clinical sample was selected on the basis of the previously described criteria, the initial assessment was carried out in two sessions. These individual assessments took place in the IPV treatment center and were conducted by clinical psychologists. The sessions took place once a week for two weeks, and the time interval between the two sessions was the same for each participant. Data related to sociodemographic characteristics and violence variables were collected in the first session through the General Structured Interview of Batterer Men. In the second session, the presence of psychopathological symptoms was assessed using the MCMI-III questionnaire.

\section{Data Analysis}

Descriptive analyses were conducted for all variables. Comparisons between the two groups were performed using $\chi^{2}$ or Student's $t$ statistics depending on the nature of the variables studied. Effect sizes (Cohen's $d$ ) were provided as follows: $d=0.20$ (small effect size), $d=0.50$ (medium effect size), and $d=0.80$ (large effect size). A logistic regression analysis (forward method) was conducted to determine which specific factors were more relevant in differentiating between participants with and without CFV. Variables that exhibited statistically significant differences in the bivariate analyses were included as independent variables. The variable entry criterion was set to 0.05 and the variable retention criterion to 0.10 . The Hosmer-Lemeshow test was used to assess the goodness of fit of these models. A difference of $p<.05$ was considered significant. Statistical analyses were carried out using SPSS (version 25.0) software.

\section{Results}

\section{Comparisons of Sociodemographic Variables and Treatment Program Access}

Table 1 shows the results of the sociodemographic variables distinguishing between IPV perpetrators with and without CFV histories. Statistically significant 
differences were found for some variables, such as education level (lower level in those with CFV), employment situation (more participants unemployed and retired among IPV perpetrators with CFV), and previous psychiatric history, such as addiction, emotional disorders, and personality disorders (more prevalent in IPV perpetrators with CFV). No statistically significant differences were found for the rest of the variables.

\section{PLACE TABLE 1 HERE}

\section{Comparisons of Psychopathological Variables}

The prevalence rate of $\mathrm{PD}$ according to a $\mathrm{BR}$ equal or higher than 85 in the MCMI-III was $35.7 \%$ in the total sample (Table 2). The scale most commonly meeting that threshold was the compulsive (21.4\%) scale, followed in smaller numbers by the narcissistic (6.1\%) and histrionic (5.5\%) scales. Comparisons between the groups with regard to the overall prevalence rate of PD showed statistically significant differences. PD were more frequently diagnosed in perpetrators without a history of CFV (37.9\%) than in those with CFV (30.4\%). With respect to each scale individually, only compulsive PD reached a statistically significant difference between groups, with a higher rate among perpetrators without $\mathrm{CFV}$.

\section{PLACE TABLE 2 HERE}

The most prevalent clinical syndromes for the total sample were anxiety $(10.7 \%)$ and drug dependence $(9.1 \%)$. Perpetrators with CFV had significantly higher prevalence rates of anxiety, bipolar, dysthymia, alcohol dependence, drug dependence, thought disorder, and major depression syndromes than those without a history of CFV (Table 2).

The results of the average scores on MCMI-III scales are shown in Table 3. On all the scales except the narcissistic scale, statistically significant differences between groups were found. The narcissistic scale scores were the most elevated for both groups, 
followed by the compulsive scale. With respect to clinical syndromes among the overall sample, the alcohol dependence scale showed the highest scores. Perpetrators with CFV were affected by almost all of the psychopathological symptoms (both PD and clinical syndromes) to a higher degree than those without CFV. The only two PD scales on which participants without a history of CFV scored higher than those with CFV were the histrionic and compulsive scales. Furthermore, with respect to modifying indices, perpetrators without CFV scored significantly higher than those with CFV on desirability and lower on disclosure and debasement scales.

\section{PLACE TABLE 3 HERE}

\section{Multivariate Analysis for Differentiating Between Perpetrators with and without}

\section{CFV}

A logistic regression analysis was performed to determine which of the MCMIIII scales were most relevant in differentiating between IPV perpetrators with and without CFV (Table 3). The results showed that the main domains related to having a history of CFV were a higher score on the disclosure and alcohol dependence scales and a lower score on the passive-aggressive scale. These variables correctly classified $70.3 \%$ of the cases.

\section{PLACE TABLE 4 HERE}

\section{Discussion}

This research was carried out to assess whether male IPV perpetrators with and without CFV presented with different psychopathological profiles. The results obtained in previous studies have shown that male perpetrators with CFV significantly differ from those without CFV on sociodemographic variables, distorted thoughts, previous psychiatric history, and personality disorders (Fernández-Montalvo et al., 2020; Green \& Browne, 2020; Lee et al., 2013). Although several studies have been focused on IPV 
perpetrators' personality traits using the MCMI questionnaire, only a few of them have explicitly attended to the presence of a family violence background (Elklit et al., 2018; Johnson et al., 2006; Murphy et al., 1993). This is the first study in which a specific sample of IPV perpetrators with and without CFV has been assessed with the MCMI-III to determine the presence of differential personality disorders and clinical syndromes. The findings support that those with CFV present with a more severe personality profile than those without CFV and that CFV, psychopathology, and IPV perpetration might be interrelated.

Similar to previous research, these results support the notion that perpetrators of IPV with CFV tend to have a lower level of education and a higher rate of unemployment (Fernández-Montalvo et al., 2020; Lee et al., 2013). The presence of previous psychiatric histories among male perpetrators has also been found in earlier investigations (Boira \& Jodrá, 2010; Fernández-Montalvo et al., 2020). In the present study, it can be concluded that psychiatric history is also related to the history of CFV. The impact of childhood maltreatment on severe life events has been widely demonstrated (Anda et al., 2006; Crouch et al., 2019). Thus, school failure, previous psychiatric history, and unemployment might represent some of the negative effects of CFV in perpetrators of IPV. Beyond these findings, additional research to examine this association is needed.

According to the results of the MCMI-III, the desirability index showed high scores for both groups, but it was significantly higher for those participants without CFV. This scale reflects the perpetrators' attempt to show themselves as socially attractive, virtuous, or composed (Millon, 1997). These rates are similar to those described in preceding studies (Catalá-Miñana et al., 2014) and highlight the relevance of attending to these scales when samples of IPV perpetrators are assessed. Since the 
logistic regression showed that disclosure was positively related to perpetrators with CFV, it may be assumed that their MCMI-III scores could reflect more precisely their psychopathological profiles, while the scores of perpetrators without $\mathrm{CFV}$ might be partially biased due to their higher rates of desirability.

The findings of this study show that $35.7 \%$ of the sample exhibited the presence of at least one PD. The rate of PD reported is higher than the $27.7 \%$ found by Corral and Calvete (2014) using the same BR cut-off score on the MCMI-III. In our study, compulsive personality disorder is the most prevalent among the overall sample (21.4\%), while the remaining PD reveal very low percentages. This is in line with Corral and Calvete (2014), who also found compulsive personality disorder as the most prevalent, although in a lower proportion (11\%). Other previous studies with different MCMI versions or with lower BR scores show similar results. For instance, FernándezMontalvo and Echeburúa (2008), using the MCMI-II, concluded that the most prevalent PD in a sample of batterer men was also compulsive personality disorder. In addition, Elklit et al. (2018), using a BR > 75 with the MCMI-III, found that none of the male IPV perpetrators of their sample scored above threshold on the compulsive scale, while the most prevalent PD was the antisocial scale. However, when these authors assessed clinical syndromes, the most prevalent was the anxiety scale, similar to findings of this study.

When average scores of MCMI-III scales are analyzed, the unique domain that did not reach a significant difference between both groups was the narcissistic personality pattern. The score in the overall sample was high, which is congruent with previous research (Catalá-Miñana et al., 2014; Corral \& Calvete, 2014; Gondolf, 1999; Walker et al., 2015). Therefore, narcissism could be considered as one of the most generalized characteristics of this population (Murrell et al., 2007). However, other 
studies have found different personality traits, such as antisocial, compulsive, passiveaggressive or depressive traits, to be more predominant than narcissism (Boira \& Jodrá, 2010; Elklit et al., 2018; Gibbons et al., 2011; Johnson et al., 2006). These heterogeneous results might be partially influenced by cultural differences of the samples, as well as by the sample source (e.g., prison, specialized treatments or general population) (Catalá-Miñana et al., 2014; Elklit et al., 2018). In any case, these differences replicate the heterogeneity of personality profiles among IPV perpetrators found in previous studies (Craig, 2003; Elklit et al., 2018; Gibbons et al., 2011) and show that there is no unique personality pattern related to them.

The results of this study show that the alcohol dependence scale is the clinical syndrome that reached the highest score among the total sample, followed by the drug dependence scale. This is consistent with literature that found alcohol abuse to be a significant variable related to IPV (Cafferky et al., 2018; Elklit et al., 2018; Murphy et al., 1993). In addition, when comparisons between groups were made, perpetrators with CFV showed significantly higher rates of alcohol dependence and drug dependence than those without CFV. Furthermore, multivariate analysis indicated that alcohol dependence was related to perpetrators with $\mathrm{CFV}$. This is particularly relevant as it emphasizes the link between CFV and alcohol dependence among IPV perpetrators (Johnson et al., 2006; Liu et al., 2012). Thus, alcohol misuse might be considered as a general risk factor for IPV perpetration but, more specifically, for those with CFV. This study also shows that not only is CFV among IPV perpetrators related to greater alcohol or substance dependence, but it is also related to a greater number of comorbid personality disorder symptoms (Elklit et al., 2018; Grover et al., 2007). However, although previous studies have concluded that perpetrators with $\mathrm{CFV}$ present with elevated scores on borderline and antisocial personality traits (Green \& Browne, 2020; 
Johnson et al., 2006; Liu et al., 2012), the findings of the present study did not support this conclusion, as the narcissistic and compulsive scales were the most salient for this group.

Regarding the logistic regression analysis, none of the personality disorders was specifically related to participants with CFV. All of them were more predominant in this group. Consequently, childhood victimization may be more related to the existence of general adult psychopathology than to a specific disordered personality (Afifi et al., 2011; Kessler et al., 2010; Marackova et al., 2016). The development of one or another personality disorder could depend on individual factors and on the type of childhood trauma (Mair et al., 2012), on the level of exposure to violence as a child (Murrell et al., 2007) or on the human functions affected (Anda et al., 2006). Hence, future research on IPV perpetrators' personality profiles should be guided by the question of whether childhood trauma has stronger implications on IPV perpetration than the type of personality disorder or whether any personality disorder type may operate as a mediator between CFV and IPV depending on additional risk factors.

\section{Limitations}

This study has some limitations that should be taken into consideration. First, the use of retrospective self-reports to assess a history of CFV may have shown underreported rates of CFV and may thereby have biased the results. Second, participants of the non-CFV group might also have been victimized, but only direct maltreatment and witnessing IPV between parents were categorized; other possible traumatic or adverse experiences in the family context during childhood (e.g., absent or rejecting parents, neglect, dysfunctional family environment) were not assessed. Third, it was not possible to identify the type and severity of the IPV perpetrated by the 
participants, which might have given relevant information to associate personality patterns with the different types of IPV. Finally, the absence of a non-IPV perpetrators control group with CFV prevents the formulation of a better adjusted profile.

Taking into account that the MCMI-IV is available since at least 5 years, the use of the MCMI-III could be considered as a limitation. However, as the data collection began in 2009 , the maintenance of the same instrument to assess all the participants with the same criteria was essential for this research and can be conceived as a key strength.

\section{Clinical Implications}

Beyond these limitations, this study contributes to expanding the notion that individualized treatment interventions should be focused on understanding the lifespan cycle of violence, from victimization to perpetration (Fang \& Corso, 2007). IPV perpetration is associated with numerous individual factors, criminogenic needs, and contextual determinants; thus, to effectively intervene, it is crucial to understand its multi-causality (Elklit et al., 2018; Gil-González et al., 2008). Psychopathological symptoms are a key point in the treatment of male IPV perpetrators, but they are not the exclusive factors due to their insufficiency in diminishing interpersonal violence. Thus, psychosocial variables linked to IPV should be the targets of specialized interventions (Novo et al., 2012) and, when necessary, be complemented by therapeutic program to treat the psychopathology (Walker et al., 2015).

In summary, this study highlights that IPV perpetrators with a history of CFV manifest a more severe personality and clinical profile than those without CFV. Hence, different patterns of IPV can be expected from each group. CFV is not the unique determinant for IPV perpetration, but it has significant implications for IPV

Siria, S., Fernández-Montalvo J., Echauri J. A., Arteaga, A., Azkárate, J.M., Martínez, M. (2021). Differential MCMI-III psychopathological profiles between intimate partner violence perpetrators with and without childhood family violence. Clinical Psychology \& Psychotherapy. https://doi.org/10.1002/cpp.2557 
progression, so the efficacy of treatment programs is reliant on their adaptation to the specific individual needs of this population. Future interventions might be specifically developed for those IPV perpetrators with CFV and be focused on their trauma exposure (Schauss et al., 2019). It has been concluded that those interventions that include the trauma component enhance the results with IPV perpetrators (Karakurt et al., 2019). 


\section{References}

Afifi, T. O., Mather, A., Boman, J., Fleisher, W., Enns, M. W., MacMillan, H., \& Sareen, J. (2011). Childhood adversity and personality disorders: Results from a nationally representative population-based study. Journal of Psychiatric Research, 45(6), 814-822. https://doi.org/10.1016/j.jpsychires.2010.11.008

Afifi, T. O., Mota, N., Sareen, J., \& MacMillan, H. L. (2017). The relationships between harsh physical punishment and child maltreatment in childhood and intimate partner violence in adulthood. Bmc Public Health, 17. https://doi.org/10.1186/s12889-017-4359-8

Anda, R. F., Felitti, V. J., Bremner, J. D., Walker, J. D., Whitfield, C., Perry, B. D., Dube, S. R., \& Giles, W. H. (2006). The enduring effects of abuse and related adverse experiences in childhood. A convergence of evidence from neurobiology and epidemiology. European Archives of Psychiatry and Clinical Neuroscience, 256(3), 174-186. https://doi.org/10.1007/s00406-005-0624-4

Arteaga, A., Fernández-Montalvo, J., \& López-Goñi, J. J. (2015). Prevalence and differential profile of patients with drug addiction problems who commit intimate partner violence. American Journal on Addictions, 24(8), 756-764. https://doi.org/10.1111/ajad.12302

Boira, S., \& Jodrá, P. (2010). Psychopathology, characteristics of violence and dropout in male batterers treatment programs: Results of an intervention service. Psicothema, 22(4), 593-599. http://www.psicothema.com/pdf/3772.pdf

Cafferky, B. M., Mendez, M., Anderson, J. R., \& Stith, S. M. (2018). Substance use and intimate partner violence: A meta-analytic review. Psychology of Violence, 8(1), 110-131. https://doi.org/10.1037/vio0000074

Cardenal, V., \& Sánchez, M. P. (2007). Adaptación y baremación al español del Inventario Clínico Multiaxial de Millon-III (MCMI-III). TEA Ediciones.

Catalá-Miñana, A., Walker, K., Bowen, E., \& Lila, M. (2014). Cultural differences in personality and aggressive behavior in intimate partner violence offenders: A comparison of English and Spanish offenders. Journal of Interpersonal Violence, 29(14), 2652-2669. https://doi.org/10.1177/0886260513517301

Corral, C., \& Calvete, E. (2014). Early maladaptive schemas and personality disorder traits in perpetrators of intimate partner violence. Spanish Journal of Psychology, 17, Article e1. https://doi.org/10.1017/sjp.2014.1

Craig, R. J. (2003). Use of the Millon Clinical Multiaxial Inventory in the psychological assessment of domestic violence: A review. Aggression and Violent Behavior, 8(3), 235-243. https://doi.org/10.1016/s1359-1789(01)00058-1

Crouch, E., Radcliff, E., Hung, P., \& Bennett, K. (2019). Challenges to school success and the role of adverse childhood experiences. Academic Pediatrics, 19(8), 899907. https://doi.org/10.1016/j.acap.2019.08.006

Davis, K. C., Masters, N. T., Casey, E., Kajumulo, K. F., Norris, J., \& George, W. H. (2018). How childhood maltreatment profiles of male victims predict adult perpetration and psychosocial functioning. Journal of Interpersonal Violence, 33(6), 915-937. https://doi.org/10.1177/0886260515613345

Echeburúa, E., \& Fernández-Montalvo, J. (1998). Instrumentos de evaluación de los maltratadores. In E. Echeburúa \& P. Corral (Eds.), Manual de violencia familiar (pp. 91-129). Siglo XXI.

Siria, S., Fernández-Montalvo J., Echauri J. A., Arteaga, A., Azkárate, J.M., Martínez, M. (2021). Differential MCMI-III psychopathological profiles between intimate partner violence perpetrators with and without childhood family violence. Clinical Psychology \& Psychotherapy. https://doi.org/10.1002/cpp.2557 
Ehrensaft, M. K., Cohen, P., \& Johnson, J. G. (2006). Development of personality disorder symptoms and the risk for partner violence. Journal of Abnormal Psychology, 115(3), 474-483. https://doi.org/10.1037/0021-843x.115.3.474

Elklit, A., Murphy, S., Jacobsen, C., \& Jensen, M. K. (2018). Clinical and personality disorders in a Danish treatment-seeking sample of intimate partner violence perpetrators. International Journal of Offender Therapy and Comparative Criminology, 62(11), 3322-3336. https://doi.org/10.1177/0306624x17741603

Fang, X. M., \& Corso, P. S. (2007). Child maltreatment, youth violence, and intimate partner violence: Developmental relationships. American Journal of Preventive Medicine, 33(4), 281-290. https://doi.org/10.1016/j.amepre.2007.06.003

Fernández-Montalvo, J., Echauri, J. A., Azcárate, J. M., Martínez, M., Siria, S., \& López-Goñi, J. J. (2020). What differentiates batterer men with and without histories of childhood family violence? Journal of Interpersonal Violence, 1-20. https://doi.org/10.1177/0886260520958648

Fernández-Montalvo, J., \& Echeburúa, E. (2008). Trastornos de personalidad y psicopatía en hombres condenados por violencia grave contra la pareja. Psicothema, 20(2), 193-198. http://psicothema.com/pdf/3447.pdf

Gibbons, P., Collins, M., \& Reid, C. (2011). How useful are indices of personality pathology when assessing domestic violence perpetrators? Psychological Assessment, 23(1), 164-173. https://doi.org/10.1037/a0021289

Gil-González, D., Vives-Cases, C., Ruiz, M. T., Carrasco-Portiño, M., \& ÁlvarezDardet, C. (2008). Childhood experiences of violence in perpetrators as a risk factor of intimate partner violence: A systematic review. Journal of Public Health, 30(1), 14-22. https://doi.org/10.1093/pubmed/fdm071

Gondolf, E. W. (1999). MCMI-III results for batterer program participants in four cities: Less "pathological" than expected. Journal of Family Violence, 14(1), 1-17. https://doi.org/10.1023/a:1022843324943

Green, K., \& Browne, K. (2020). Personality disorder traits, trauma, and risk in perpetrators of domestic violence. International Journal of Offender Therapy and Comparative Criminology, 64(2-3), 147-166. https://doi.org/10.1177/0306624x19826516

Grover, K. E., Carpenter, L. L., Price, L. H., Gagne, G. G., Mello, A. F., Mello, M. F., \& Tyrka, A. R. (2007). The relationship between childhood abuse and adult personality disorder symptoms. Journal of Personality Disorders, 21(4), 442447. https://doi.org/10.1521/pedi.2007.21.4.442

Grusnick, J. M., Garacci, E., Eiler, C., Williams, J. S., \& Egede, L. E. (2020). The association between adverse childhood experiences and personality, emotions and affect: Does number and type of experiences matter? Journal of Research in Personality, 85, 1-8. https://doi.org/10.1016/j.jrp.2019.103908

Hilton, N. Z., Ham, E., \& Green, M. M. (2019). Adverse childhood experiences and criminal propensity among intimate partner violence offenders. Journal of Interpersonal Violence, 34(19), 4137-4161. https://doi.org/10.1177/0886260516674943

Johnson, R., Gilchrist, E., Beech, A. R., Weston, S., Takriti, R., \& Freeman, R. (2006). A psychometric topology of UK domestic violence offenders. Journal of Interpersonal Violence, 21(10), 1270-1285. https://doi.org/10.1177/0886260506291655

Karakurt, G., Koc, E., Cetinsaya, E. E., Ayluctarhan, Z., \& Bolen, S. (2019). Metaanalysis and systematic review for the treatment of perpetrators of intimate

Siria, S., Fernández-Montalvo J., Echauri J. A., Arteaga, A., Azkárate, J.M., Martínez, M. (2021). Differential MCMI-III psychopathological profiles between intimate partner violence perpetrators with and without childhood family violence. Clinical Psychology \& Psychotherapy. https://doi.org/10.1002/cpp.2557 
partner violence. Neuroscience and Biobehavioral Reviews, 105, 220-230. https://doi.org/10.1016/j.neubiorev.2019.08.006

Kessler, R. C., McLaughlin, K. A., Green, J. G., Gruber, M. J., Sampson, N. A., Zaslavsky, A. M., Aguilar-Gaxiola, S., Alhamzawi, A. O., Alonso, J., Angermeyer, M., Benjet, C., Bromet, E., Chatterji, S., de Girolamo, G., Demyttenaere, K., Fayyad, J., Florescu, S., Gal, G., Gureje, O., Haro, J. M., Hu, C. Y., Karam, E. G., Kawakami, N., Lee, S., Lepine, J. P., Ormel, J., PosadaVilla, J., Sagar, R., Tsang, A., Ustun, T. B., Vassilev, S., Viana, M. C., \& Williams, D. R. (2010). Childhood adversities and adult psychopathology in the WHO World Mental Health Surveys. British Journal of Psychiatry, 197(5), 378385. https://doi.org/10.1192/bjp.bp.110.080499

Lee, R. D., Walters, M. L., Hall, J. E., \& Basile, K. C. (2013). Behavioral and attitudinal factors differentiating male intimate partner violence perpetrators with and without a history of childhood family violence. Journal of Family Violence, 28(1), 85-94. https://doi.org/10.1007/s10896-012-9475-8

Liu, N., Zhang, Y. L., Brady, H. J., Cao, Y. P., \& He, Y. (2012). Relation between childhood maltreatment and severe intrafamilial male-perpetrated physical violence in Chinese community: The mediating role of borderline and antisocial personality disorder features. Aggressive Behavior, 38(1), 64-76. https://doi.org/10.1002/ab.20417

Mair, C., Cunradi, C. B., \& Todd, M. (2012). Adverse childhood experiences and intimate partner violence: Testing psychosocial mediational pathways among couples. Annals of Epidemiology, 22(12), 832-839. https://doi.org/10.1016/j.annepidem.2012.09.008

Marackova, M., Prasko, J., Matousek, S., Latalova, K., Hruby, R., Holubova, M., Slepecky, M., Vrbova, K., \& Grambal, A. (2016). The impact of childhood adversities on anxiety and depressive disorders in adulthood. Neuroendocrinology Letters, 37(7), 478-484.

Millon, T. (1997). Millon Clinical Multiaxial Inventory-III (MCMI-III). National Computer Systems.

Murphy, C. M., Meyer, S. L., \& O'Leary, K. D. (1993). Family of origin violence and MCMI-II psychopathology among partner assaultive men. Violence and victims, 8(2), 165-176.

Murrell, A. R., Christoff, K. A., \& Henning, K. R. (2007). Characteristics of domestic violence offenders: Associations with childhood exposure to violence. Journal of Family Violence, 22(7), 523-532. https://doi.org/10.1007/s10896-007-9100-4

Novo, M., Farina, F., Seijo, M. D., \& Arce, R. (2012). Assessment of a community rehabilitation programme in convicted male intimate-partner violence offenders. International Journal of Clinical and Health Psychology, 12(2), 219-234.

Okuda, M., Olfson, M., Wang, S., Rubio, J. M., Xu, Y., \& Blanco, C. (2015). Correlates of intimate partner violence perpetration: Results from a national epidemiologic survey. Journal of Traumatic Stress, 28(1), 49-56. https://doi.org/10.1002/jts.21986

Roberts, A. L., McLaughlin, K. A., Conron, K. J., \& Koenen, K. C. (2011). Adulthood stressors, history of childhood adversity, and risk of perpetration of intimate partner violence. American Journal of Preventive Medicine, 40(2), 128-138. https://doi.org/10.1016/j.amepre.2010.10.016

Schauss, E., Zettler, H. R., \& Russell, A. (2019). Examining ACTV: An argument for implementing neuroscience-based and trauma-informed treatment models in 
offender treatment programs. Aggression and Violent Behavior, 46, 1-7. https://doi.org/10.1016/j.avb.2019.01.002

Shorey, R. C., Febres, J., Brasfield, H., \& Stuart, G. L. (2012). The prevalence of mental health problems in men arrested for domestic violence. Journal of Family Violence, 27(8), 741-748. https://doi.org/10.1007/s10896-012-9463-z

Walker, K., Bowen, E., Brown, S., \& Sleath, E. (2015). An examination of psychopathology among men who have suspended the use of violence in their intimate relationships. Journal of Family Violence, 30(5), 539-554. https://doi.org/10.1007/s10896-015-9694-X

Weber, T., \& Bouman, Y. H. A. (2020). Intimate partner violence: Variations in perpetrators and treatment allocation. Journal of Interpersonal Violence, 35(34), 1012-1034. https://doi.org/10.1177/0886260517692994 


\section{Table 1}

Results of Sociodemographic Variables and Treatment Program Access

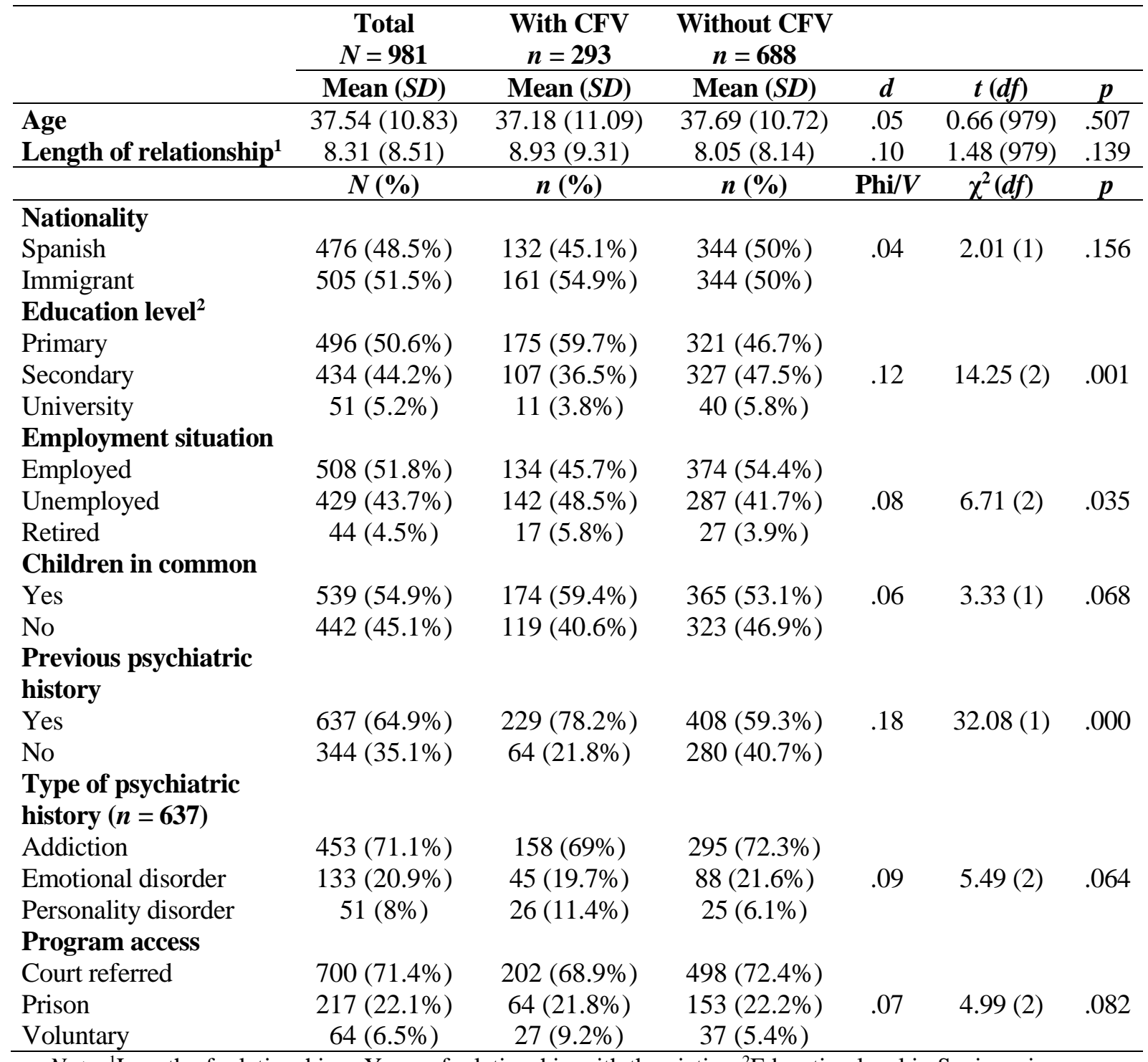

Note. ${ }^{1}$ Length of relationship $=$ Years of relationship with the victim. ${ }^{2}$ Education level in Spain: primary studies (3-12 years old), secondary studies (12-18 years old), university (>18 years old).

For those contingency tables with two categories Phi value was calculated, and for those with three or more categories, Cramer's $V$ was calculated.

Siria, S., Fernández-Montalvo J., Echauri J. A., Arteaga, A., Azkárate, J.M., Martínez, M. (2021). Differential MCMI-III psychopathological profiles between intimate partner violence perpetrators with and without childhood family violence. Clinical Psychology \& Psychotherapy. https://doi.org/10.1002/cpp.2557 


\section{Table 2}

Prevalence of the MCMI-III Personality Disorders (Base Rate $\geq 85$ )

\begin{tabular}{|c|c|c|c|c|c|c|}
\hline & $\begin{array}{c}\text { Total } \\
N=981 \\
\end{array}$ & $\begin{array}{c}\text { With CFV } \\
n=293 \\
\end{array}$ & $\begin{array}{c}\text { Without CFV } \\
n=688 \\
\end{array}$ & & & \\
\hline & $N(\%)$ & $n(\%)$ & $n(\%)$ & Phi & $\chi^{2}(d f)$ & $p$ \\
\hline \multicolumn{7}{|l|}{ Modifying indices } \\
\hline Disclosure & $56(5.7 \%)$ & $28(9.6 \%)$ & $28(4.1 \%)$ & .108 & $11.49(1)$ & .001 \\
\hline Desirability & $429(43.7 \%)$ & $107(36.5 \%)$ & $322(46.8 \%)$ & .095 & $8.83(1)$ & .003 \\
\hline Debasement & $36(3.7 \%)$ & $14(4.8 \%)$ & $22(3.2)$ & .038 & $1.45(1)$ & .228 \\
\hline \multicolumn{7}{|l|}{$\begin{array}{l}\text { Personality disorder } \\
\text { scales }\end{array}$} \\
\hline Schizoid & $3(0.3 \%)$ & $1(0.3 \%)$ & $2(0.3 \%)$ & .004 & $0.02(1)$ & .895 \\
\hline Avoidant & $4(0.4 \%)$ & $2(0.7 \%)$ & $2(0.3 \%)$ & .028 & $0.78(1)$ & .378 \\
\hline Depressive & $4(0.4 \%)$ & $2(0.7 \%)$ & $2(0.3 \%)$ & .028 & $0.78(1)$ & .378 \\
\hline Dependent & $3(0.3 \%)$ & $2(0.7 \%)$ & $1(0.1 \%)$ & .045 & $1.94(1)$ & .163 \\
\hline Histrionic & $54(5.5 \%)$ & $10(3.4 \%)$ & $44(6.4 \%)$ & .060 & $3.51(1)$ & .061 \\
\hline Narcissistic & $60(6.1 \%)$ & $19(6.5 \%)$ & $41(6.0 \%)$ & .010 & $0.10(1)$ & .753 \\
\hline Antisocial & $12(1.2 \%)$ & $4(1.4 \%)$ & $8(1.2 \%)$ & .008 & $0.07(1)$ & .792 \\
\hline Aggressive & $5(0.5 \%)$ & $2(0.7 \%)$ & $3(0.4 \%)$ & .016 & $0.25(1)$ & .620 \\
\hline Compulsive & $210(21.4 \%)$ & $51(17.4 \%)$ & $159(23.1 \%)$ & .064 & $3.97(1)$ & .046 \\
\hline Passive-aggressive & $1(0.1 \%)$ & $1(0.3 \%)$ & -- & .049 & $2.35(1)$ & .125 \\
\hline Self-defeating & -- & -- & -- & -- & -- & -- \\
\hline Schizotypal & $6(0.6 \%)$ & $3(1.0 \%)$ & $3(0.4 \%)$ & .035 & $1.17(1)$ & .280 \\
\hline Borderline & $4(0.4 \%)$ & $2(0.7 \%)$ & $2(0.3 \%)$ & .028 & $0.78(1)$ & .378 \\
\hline Paranoid & $13(1.3 \%)$ & $7(2.4 \%)$ & $6(0.9 \%)$ & .061 & $3.62(1)$ & .057 \\
\hline TOTAL $^{1}$ & $350(35.7 \%)$ & $89(30.4 \%)$ & $261(37.9 \%)$ & .072 & $5.12(1)$ & .024 \\
\hline \multicolumn{7}{|l|}{$\begin{array}{l}\text { Clinical syndrome } \\
\text { scales }\end{array}$} \\
\hline Anxiety & $105(10.7 \%)$ & $48(16.4 \%)$ & $57(8.3 \%)$ & .120 & $14.10(1)$ & .000 \\
\hline Somatoform & $5(0.5 \%)$ & $2(0.7 \%)$ & $3(0.4 \%)$ & .016 & $0.25(1)$ & .620 \\
\hline Bipolar & $19(1.9 \%)$ & $10(3.4 \%)$ & $9(1.3 \%)$ & .070 & $4.79(1)$ & .029 \\
\hline Dysthymia & $8(0.8 \%)$ & $5(1.7 \%)$ & $3(0.4 \%)$ & .065 & $4.10(1)$ & .043 \\
\hline Alcohol dependence & $38(3.9 \%)$ & $23(7.8 \%)$ & $15(2.2 \%)$ & .134 & $17.74(1)$ & .000 \\
\hline Drug dependence & $89(9.1 \%)$ & $40(13.7 \%)$ & $49(7.1 \%)$ & .104 & $10.62(1)$ & .001 \\
\hline PTSD & $7(0.7 \%)$ & $4(1.4 \%)$ & $3(0.4 \%)$ & .051 & $2.50(1)$ & .114 \\
\hline Thought disorder & $42(4.3 \%)$ & $19(6.5 \%)$ & $23(3.3 \%)$ & .071 & $4.95(1)$ & .026 \\
\hline Major depression & $26(2.7 \%)$ & $13(4.4 \%)$ & $13(1.9 \%)$ & .073 & $5.17(1)$ & .023 \\
\hline Delusional disorder & $20(2 \%)$ & $8(2.7 \%)$ & $12(1.7 \%)$ & .032 & $1.00(1)$ & .317 \\
\hline
\end{tabular}

Note. ${ }^{1}$ The total number of people affected by personality disorders is less than the total sum of disorders because there are participants who present with more than one personality disorder.

Siria, S., Fernández-Montalvo J., Echauri J. A., Arteaga, A., Azkárate, J.M., Martínez, M. (2021). Differential MCMI-III psychopathological profiles between intimate partner violence perpetrators with and without childhood family violence. Clinical Psychology \& Psychotherapy. https://doi.org/10.1002/cpp.2557 


\section{Table 3}

Average Scores on the MCMI-III Scales

\begin{tabular}{|c|c|c|c|c|c|c|}
\hline & $\begin{array}{c}\text { Total } \\
N=981 \\
\end{array}$ & $\begin{array}{c}\text { With CFV } \\
n=293\end{array}$ & $\begin{array}{c}\text { Without CFV } \\
n=688 \\
\end{array}$ & & & \\
\hline & $M(S D)$ & $M(S D)$ & $M(S D)$ & $d$ & $t(d f)$ & $p$ \\
\hline \multicolumn{7}{|l|}{ Modifying indices } \\
\hline Disclosure & $48.50(21.02)$ & $54.98(20.92)$ & $45.74(20.47)$ & .44 & $6.43(979)$ & .000 \\
\hline Desirability & $77.20(16.22)$ & $73.86(17.29)$ & $78.62(15.54)$ & .29 & $4.25(979)$ & .000 \\
\hline Debasement & $43.64(23.32)$ & $48.63(23.12)$ & $41.51(23.09)$ & .30 & $4.42(979)$ & .000 \\
\hline \multicolumn{7}{|l|}{$\begin{array}{l}\text { Personality disorder } \\
\text { scales }\end{array}$} \\
\hline Schizoid & $40.66(21.51)$ & $45.53(20.21)$ & $38.58(21.73)$ & .32 & $4.68(979)$ & .000 \\
\hline Avoidant & $35.50(23.46)$ & $39.68(23.85)$ & $33.72(23.09)$ & .25 & $3.66(979)$ & .000 \\
\hline Depressive & $31.80(25.61)$ & $37.74(26.78)$ & $29.27(24.69)$ & .33 & $4.64(979)$ & .000 \\
\hline Dependent & $37.91(20.37)$ & $42.12(20.34)$ & $36.11(20.14)$ & .29 & $4.26(979)$ & .000 \\
\hline Histrionic & $50.98(18.57)$ & $47.25(18.91)$ & $52.56(18.20)$ & .28 & 4.13 (979) & .000 \\
\hline Narcissistic & $67.38(12.49)$ & $66.37(14.60)$ & $67.82(11.46)$ & .12 & $1.51(979)$ & .131 \\
\hline Antisocial & $47.49(22.32)$ & $51.63(21.54)$ & $45.73(22.42)$ & .26 & $3.82(979)$ & .000 \\
\hline Aggressive & $39.18(22.95)$ & $45.51(21.68)$ & $36.49(22.96)$ & .39 & $5.86(979)$ & .000 \\
\hline Compulsive & $61.67(21.13)$ & $59.45(21.56)$ & $62.62(20.89)$ & .15 & $2.15(979)$ & .031 \\
\hline Passive-aggressive & $39.94(22.95)$ & $44.07(22.01)$ & $38.18(23.13)$ & .26 & $3.70(979)$ & .000 \\
\hline Self-defeating & $32.12(24.27)$ & $38.32(23.50)$ & $29.48(24.13)$ & .36 & $5.29(979)$ & .000 \\
\hline Schizotypal & $31.52(26.39)$ & $37.86(26.07)$ & $28.82(26.08)$ & .34 & 4.97 (979) & .000 \\
\hline Borderline & $34.90(24.78)$ & $40.03(24.44)$ & $32.71(24.61)$ & .29 & 4.27 (979) & .000 \\
\hline Paranoid & $46.59(26.68)$ & $52.81(24.80)$ & $43.94(27.03)$ & .33 & $4.99(979)$ & .000 \\
\hline \multicolumn{7}{|l|}{$\begin{array}{l}\text { Clinical syndrome } \\
\text { scales }\end{array}$} \\
\hline Anxiety & $41.70(33.93)$ & $48.41(34.00)$ & $38.84(33.51)$ & .28 & $4.08(979)$ & .000 \\
\hline Somatoform & $29.71(26.93)$ & $34.16(27.17)$ & $27.81(26.62)$ & .23 & $3.40(979)$ & .001 \\
\hline Bipolar & $48.38(22.76)$ & $52.42(22.00)$ & $46.66(22.88)$ & .25 & $3.71(979)$ & .000 \\
\hline Dysthymia & $29.53(27.02)$ & $35.01(27.97)$ & $27.20(26.28)$ & .29 & 4.07 (979) & .000 \\
\hline Alcohol dependence & $52.92(22.72)$ & $58.61(22.43)$ & $50.50(22.43)$ & .36 & $5.18(979)$ & .000 \\
\hline Drug dependence & $49.23(27.49)$ & $55.06(27.86)$ & 46.75 (26.97) & .30 & 4.37 (979) & .000 \\
\hline PTSD & $29.65(25.71)$ & $35.74(26.74)$ & $27.06(24.84)$ & .34 & $4.75(979)$ & .000 \\
\hline Thought disorder & $32.25(28.82)$ & $38.58(30.53)$ & $29.55(27.64)$ & .31 & $4.36(979)$ & .000 \\
\hline Major depression & $29.51(28.61)$ & $34.81(29.56)$ & $27.26(27.92)$ & .26 & $3.81(979)$ & .000 \\
\hline Delusional disorder & $48.61(30.72)$ & $55.78(27.32)$ & $45.56(31.59)$ & .33 & $5.11(979)$ & .000 \\
\hline
\end{tabular}

Siria, S., Fernández-Montalvo J., Echauri J. A., Arteaga, A., Azkárate, J.M., Martínez, M. (2021). Differential MCMI-III psychopathological profiles between intimate partner violence perpetrators with and without childhood family violence. Clinical Psychology \& Psychotherapy. https://doi.org/10.1002/cpp.2557 


\section{Table 4}

Multivariate Analysis for Differentiating Between Perpetrators with and without CFV

\begin{tabular}{llccc}
\hline & Variable & OR & $\boldsymbol{p}$ & 95\% CI \\
\hline & Disclosure & 1.025 & $<.001$ & $(1.013-1.036)$ \\
& Alcohol dependence & 1.009 & .023 & $(1.001-1.017)$ \\
& Passive-aggressive & .990 & .049 & $(.981-1.000)$ \\
& Constant & .115 & $<.001$ & \\
\hline Adjusted R & .068 & & & \\
Correctly & $70.3 \%$ & $6.8 \%$ & $97.4 \%$ & \\
classified & (Total) & (With CFV) & (Without CFV) & \\
\hline
\end{tabular}

Note. Dependent variable $=\mathrm{CFV} ; 0=$ No; $1=$ Yes. Only the final model is presented.

Siria, S., Fernández-Montalvo J., Echauri J. A., Arteaga, A., Azkárate, J.M., Martínez, M. (2021). Differential MCMI-III psychopathological profiles between intimate partner violence perpetrators with and without childhood family violence. Clinical Psychology \& Psychotherapy. https://doi.org/10.1002/cpp.2557 